\title{
Radiocarbon
}

1981

\section{FRACTIONATION CORRECTIONS IN RADIOCARBON DATING}

\author{
T M L WIGLEY \\ Climatic Research Unit, University of East Anglia \\ Norwich NR4 7TJ, U K \\ and \\ A B MULLER* \\ Laboratory of Isotope Geochemistry, University of Arizona \\ Tucson, Arizona 85721
}

ABSTRACT. Recent experimental work has suggested that the relative fractionation of ${ }^{14} \mathrm{C}$ to ${ }^{13} \mathrm{C}$ may differ from the accepted value of $\mathrm{b}=2$. In order to explore the implications of this possibility, the standard formulae for correcting radiocarbon dates for fractionation effects are rederived, but without making any of the usual assumptions or approximations. A generalized dating equation

$$
A_{\mathrm{SN}}=\beta\left\{\frac{\mathrm{R}_{\mathrm{ST}}^{\left({ }^{(0)}\right.}}{\mathbf{R}_{\mathrm{ST}}}\right\}^{\mathrm{b}} \quad \mathrm{A}_{\mathrm{ON}} \exp \left(-\mathrm{t}_{\mathrm{ca} 1} / 8267\right)
$$

is derived (where $A_{S N}$ and $A_{O N}$ are normalized sample and standard activities, $\beta$ is a factor which reflects changes in atmospheric ${ }^{12} \mathrm{C}$ and ${ }^{14} \mathrm{C}$ content, $\left\{\mathbf{R}_{\mathrm{ST}}{ }^{(0)} / \mathbf{R}_{\mathrm{ST}}\right\}^{\mathrm{b}}$ accounts for post-depositional changes in sample ${ }^{12} \mathrm{C}$ ratio, and $t_{c a l}$ is calendar age in years before AD 1950. The errors in calculated ages which might arise from different $b$ values are estimated and shown to be small relative to other dating uncertainties. The effect of $b \neq 2$ may be important in the calibration of radiocarbon dates using tree-ring samples of known age. A theoretical analysis suggests that $b \neq 2$ effects may result in a correlation between age anomaly (ie, the difference between radiocarbon age and calendar age) and sample ${ }^{13} \mathrm{C}$ data. However, an analysis of published data reveals no meaningíul correlation. This result, while not eliminating the possibility that $\mathrm{b} \neq 2$, highlights its unimportance even in this high-precision application of radiocarbon dating.

\section{TERMINOLOGY}

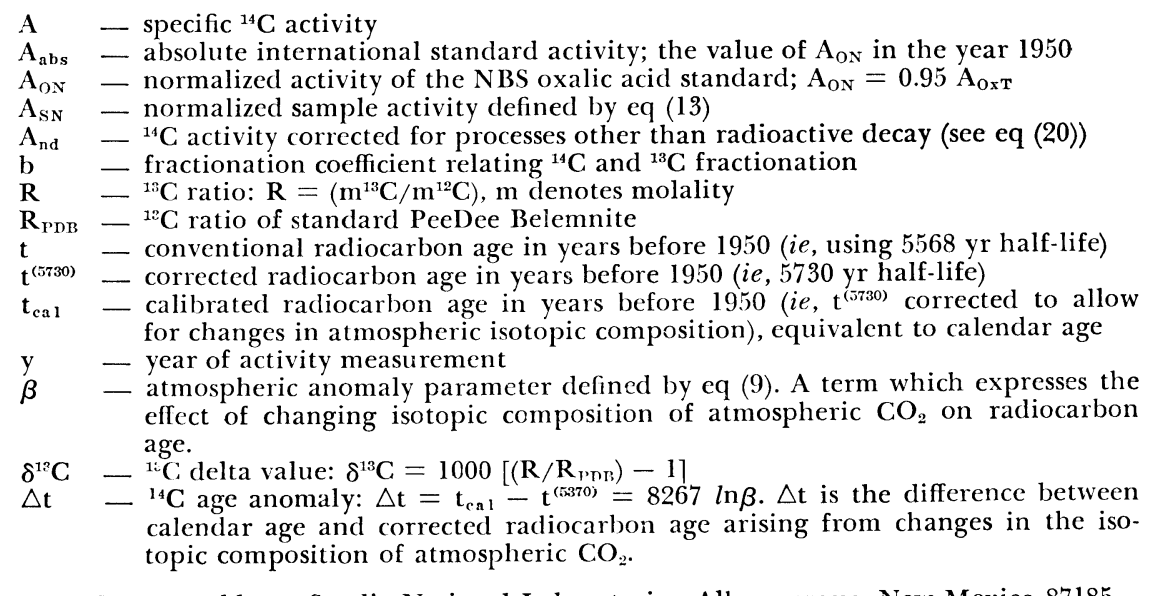

* Present address: Sandia National Laboratories, Albuquerque, New Mexico 87185 
$\Delta \mathrm{t}_{\mathrm{cal}}$ - incremental change in $\mathrm{t}_{\mathrm{cal}}$ due to a change in b (see eq (26))

$\xi \quad$ - correction factor for non-decay processes defined by eq (21)

Subscripts

S - measured sample value (ie, including changes induced by laboratory fractionation effects during preparation for counting)

ST - true sample value; the value prior to preparation

$\mathrm{Ox}$ - measured value of oxalic acid standard (ie, including preparation fractiona-

OxT - true value of oxalic acid standard, prior to preparation

atm T - true value of atmospheric $\mathrm{CO}_{2}$

Superscripts

(o) - initial value; $i e$, value at time of death of a sample, $\mathrm{t}_{\mathrm{ca} 1}$ years before 1950
- value during the standard "zero" year, 1950

\section{INTRODUCTION}

In ${ }^{14} \mathrm{C}$ dating, measured activities are corrected for natural isotopic fractionation during the formation of the sample, and for laboratory fractionation during sample preparation. These corrections are made using stable isotope data $\left({ }^{13} \mathrm{C}\right)$ and are based on the relationship between ${ }^{14} \mathrm{C}$ fractionation and ${ }^{13} \mathrm{C}$ fractionation:

$$
A_{1} / A_{2}=\left\{R_{1} / R_{2}\right\}^{b}
$$

where $A_{1}$ and $A_{2}$ are specific ${ }^{14} \mathrm{C}$ activities of a sample before and after a fractionation process, and $R_{1}$ and $R_{2}$ are the corresponding ${ }^{13} \mathrm{C}$ ratios. It is accepted practice to assume for equilibrium isotopic exchange reactions that $b=2$, based on the well-known approximate relationship between fractionation and mass number difference (Craig, 1954).

Recent work by Radnell (1980) and Saliège (Saliège and Fontes, ms in preparation) has reopened the question of the accuracy of this assumption, a question considered briefly by Stuiver and Robinson (1974). The experimental works of Radnell and of Saliège suggest that $b$ may be significantly greater than 2 and may even depend on the reaction path and, hence, on the type of sample analyzed and the method of analysis. In this paper we do not attempt to determine whether $b=2$ or to confirm these experimental results, but, rather, we examine the possible significance of these findings. In particular, we estimate the errors in estimated ages which might arise from different $b$ values.

It is important to note here that if $b$ does vary significantly from 2 , this variation is due to physico-chemical mechanisms which are not mass (or mass difference) dependent, and which have, therefore, not been accounted for by the classical statistical thermodynamic treatment of Urey (1947), Bigeleisen and Mayer (1947), and more recently Richet, Bottinga, and Javoy (1977). One such mechanism which has been suggested (Galimov, 1978) calls upon the difference in nuclear spin between magnetic (eg, ${ }^{13} \mathrm{C},{ }^{17} \mathrm{O}$ ) and non-magnetic nuclei $\left(\mathrm{eg},{ }^{14} \mathrm{C},{ }^{12} \mathrm{C},{ }^{18} \mathrm{O},{ }^{16} \mathrm{O}\right)$. Hyperfine coupling in magnetic isotopes enhances free radical recombination reactions and leads to a mass-difference-independent enrichment of the magnetic isotope. In the case of oxygen isotopes, Thiemens and Clayton (1979) have been unable to reproduce Galimov's experimental results for 
${ }^{17} \mathrm{O}$ under natural conditions. However, the phenomenon has been demonstrated for ${ }^{13} \mathrm{C}$ by Turro and Traeutler (1978), in the ${ }^{13} \mathrm{C}$ enrichment of the carbonyl carbon during photolysis of dibenzyl ketone. Turro and Traeutler's work shows that the magnitude of the effect depends on the strength of the magnetic field and on the physical and chemical nature of the compound. There is no evidence that it is important in the materials or reactions of ${ }^{14} \mathrm{C}$ dating. Furthermore, since ${ }^{13} \mathrm{C}$ is enriched relative to the non-magnetic isotopes ${ }^{12} \mathrm{C}$ and ${ }^{14} \mathrm{C}$, the effect of hyperfine coupling (ie, the nuclear spin effect) would be to reduce b below 2 ( $c f$ Stuiver and Robinson, 1974) and we are still left without an explanation of Radnell's and Saliège's results.

In order to analyze the effect of different $b$ values on ${ }^{14} \mathrm{C}$ ages, it is necessary to rederive the standard formulae which are used to calculate ${ }^{14} \mathrm{C}$ ages from measured ${ }^{14} \mathrm{C}$ activities, but without making any of the usual assumptions or approximations. It is clear that if some mass independent mechanism existed which would preferentially affect only ${ }^{13} \mathrm{C} /{ }^{12} \mathrm{C}$ or ${ }^{14} \mathrm{C} /{ }^{12} \mathrm{C}$ fractionation so that $\mathrm{b}$ would diverge from 2 , then the number of passes through such a mechanism would determine the ultimate difference in fractionations. Further, if $\mathrm{b}$ is reaction- or processdependent, each mechanism could have a unique value of $b$ which would combine in a complex multi-process system. For simplicity, our treatment deals only with a single pass, single process fractionation, and we assume that $\mathrm{b}$ is constant, but not necessarily equal to 2 .

\section{${ }^{14} \mathrm{C}$ AGE ESTIMATION}

This section gives a summary of the recommended procedures for reporting the results of ${ }^{14} \mathrm{C}$ analysis. A very useful summary has already been given by Stuiver and Polach (1977), but their work is rather brief in its explanation of the various procedures. Some of these procedures have been developed over the years and their history is not readily accessible to the novice who seeks to understand "why" as well as "how". Furthermore, approximations are frequently used and this can tend to obscure some important underlying assumptions. In the following we will attempt to give a self-contained and coherent account of the procedure for reporting ${ }^{14} \mathrm{C}$ dates which contains no approximations. The results show clearly how various commonly used approximations may affect ${ }^{14} \mathrm{C}$ dates.

The basic premise of the ${ }^{14} \mathrm{C}$ dating method, developed by Libby in the late 1940s, is that the atmosphere contains a relatively constant reservoir of the radioactive isotope ${ }^{14} \mathrm{C}$ in atmospheric carbon dioxide. This near-constant level is the result of a balance between the production of ${ }^{14} \mathrm{C}$ (by secondary neutrons generated in spallation reactions in the upper atmosphere by cosmic ray bombardment), the redistribution of various carbon compounds between the atmosphere, oceans, and biosphere, and the loss of ${ }^{14} \mathrm{C}$ by radioactive decay. Since living materials constantly recycle carbon with their environment, they contain an amount of ${ }^{14} \mathrm{C}$ which is in equilibrium with, but not necessarily equal to that 
contained in atmospheric carbon dioxide. When living materials die, the interchange of ${ }^{14} \mathrm{C}$ ceases and the amount contained in the organism begins to diminish by radioactive decay. By measuring the ${ }^{14} \mathrm{C}$ content we can determine the time which has elapsed since death ${ }^{1}$ assuming that there has been no "contamination" of the sample by exchange with other ${ }^{14} \mathrm{C}$ reservoirs after death.

The amount of ${ }^{14} \mathrm{C}$ in a sample is measured by counting the number of radioactive disintegrations per unit mass and unit time (ie, the "count rate", or "specific activity") and comparing this with an international standard which in turn is related to the "initial" activity of the sample at death. In principle, a knowledge of the activity of a sample measured in year y should determine its age via the decay equation

$$
A_{\mathrm{ST}}=A_{\mathrm{ST}}{ }^{(0)} 2^{-\left(\mathrm{t}_{\mathrm{cal}}+\mathrm{y}-1950\right) / 5730}=\mathrm{A}_{\mathrm{ST}^{(}{ }^{(0)}} \exp \left(-\left(\mathrm{t}_{\mathrm{cal}}+\mathrm{y}-1950\right) / 8267\right)
$$

where $A_{\mathrm{ST}}$ is the sample activity, $\mathrm{A}_{\mathrm{ST}}{ }^{(0)}$ is the initial sample activity and $\mathbf{t}_{\mathrm{cal}}$ is its true (ie, calendar) age (see below). 5730 years is the half-life of ${ }^{14} \mathrm{C} ; 8267$ years $(\equiv 5730 / \ln 2)$ is the mean life. In practice, things are not so simple and four main difficulties arise.

1) The convention is to use an early estimate of the half-life (viz 5570 or 5568 years) which has subsequently been revised (to 5730 years). This facilitates comparison between ages determined today and ages determined prior to the revised half-life estimation. There are, therefore, two different ${ }^{14} \mathrm{C}$ ages: the conventional radiocarbon age, $\mathrm{t}$, determined using the old half-life, and the corrected radiocarbon age, $\mathrm{t}^{(5730)}$, determined using the 5730-year half-life. The two are related by $t^{(5730)}=$ $1.029 \mathrm{t}$.

2) The assumption of a constant atmospheric ${ }^{14} \mathrm{C}$ level is not strictly correct. In principle, an empirically determined correction can be applied, either to $\mathrm{t}$ or to $\mathrm{t}^{(5730)}$, to account for variations in atmospheric ${ }^{14} \mathrm{C}$ level; leading to a calibrated radiocarbon age which is directly identifiable with the calendar age, $\mathrm{t}_{\mathrm{cal}}$. In practice, this requires an accurate knowledge of past atmospheric ${ }^{14} \mathrm{C}$ variations, and work on building up this important paleorecord is still in progress (eg, Suess, 1980; Stuiver and Quay, 1980).

3) The measured activity, $A_{S}$, is generally not precisely the same as the true sample activity, $i e$, the value prior to sample preparation, $\mathrm{A}_{\mathrm{ST}}$. This difference arises because of isotopic fractionation in the chemical reactions involved in preparation of a sample for measurement. If the yield of any preparation step is not $100 \%$, then there will be a residual laboratory fractionation which manifests itself as a change in ${ }^{14} \mathrm{C}$ content. The effect can be accounted for by using ${ }^{13} \mathrm{C}$ data. Equation (1) implies

$$
\mathrm{A}_{\mathrm{ST}}=\mathrm{A}_{\mathrm{S}}\left\{\mathrm{R}_{\mathrm{ST}} / \mathrm{R}_{\mathrm{S}}\right\}^{\mathrm{b}}
$$

${ }^{1}$ For groundwater and other materials which may have been altered isotopically by identifiable chemical or physical processes, the measurable time is that which has elapsed since isolation from the main atmospheric ${ }^{14} \mathrm{C}$ reservoir. These cases will be discussed separately. 
The necessary correction to account for laboratory fractionation cannot (and need not) be separated from the natural fractionation correction (item (4) below).

4) In order to apply equation (2), $\mathrm{A}_{\mathrm{ST}}{ }^{(0)}$ must be determined. Although the sample may have been in equilibrium with the atmospheric ${ }^{14} \mathrm{C}$ reservoir at the time of death, its ${ }^{14} \mathrm{C}$ activity at this time will not, in general, have been the same as that of the atmosphere. A natural fractionation correction must be applied to account for this difference. In practice, this correction is not separated from the laboratory fractionation correction.

We will now derive a practical dating equation. Although the fundamental standard for ${ }^{14} \mathrm{C}$ dating is the atmospheric level, in order to use this standard, $\mathrm{A}_{\mathrm{ST}}{ }^{(0)}$ in equation (2) must be related to a laboratory reference standard which bears a known relationship to the atmospheric level. The most commonly used standard today is a specially prepared oxalic acid whose activity, $A_{O x T}$, has been defined after comparison with an age-corrected pre-industrial (AD 1890 tree rings) wood sample ${ }^{2}$. The links between $A_{\mathrm{ST}^{(0)}}{ }^{(0)}$ and $\mathrm{A}_{\mathrm{OxT}}$ are shown in the following flow diagram (where * denotes the value in the standard "zero" year for ${ }^{14} \mathrm{C}$ dating, AD 1950):

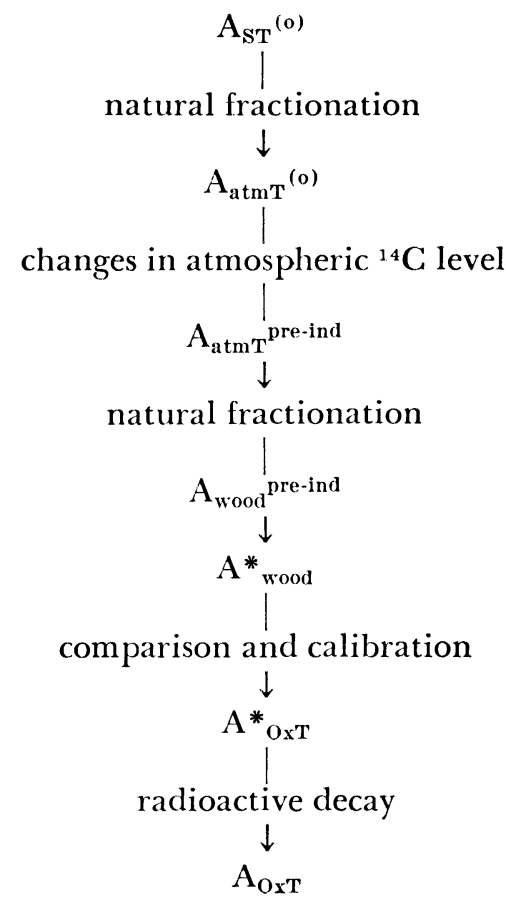

2 A new standard is to be introduced shortly, but the arguments presented here apply equally to any standard provided numerical quantities are adjusted appropriately. 
For the first few links in this chain we have, from equation (1),

$$
\begin{aligned}
& \mathrm{A}_{\mathrm{ST}}{ }^{(0)}=\mathrm{A}_{\mathrm{atmT}}{ }^{(0)}\left\{\mathrm{R}_{\mathrm{ST}}{ }^{(0)} / \mathrm{R}_{\mathrm{atmT}}{ }^{(0)}\right\}^{\mathrm{b}}
\end{aligned}
$$

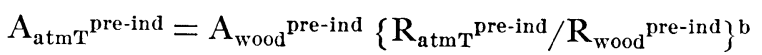

where, by definition, $\mathrm{R}_{\text {wood }}{ }^{\text {pre-ind }} \equiv 0.975 \mathrm{R}_{\mathrm{PDB}} \quad\left(i e, \delta^{13} \mathrm{C}_{\text {wood }}{ }^{\text {pre-ind }} \equiv\right.$ $-25 \%$ орDB $)$. To relate the pre-industrial wood sample to conditions which should have prevailed in the year AD 1950, were it not for post-industrial perturbations of the carbon isotope composition of the atmosphere, equation (5) can be rewritten as

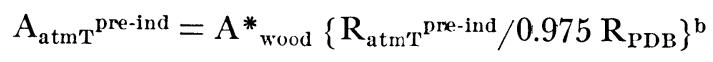

Here $\mathrm{A}^{*}{ }_{\text {wood }}$ is the age-corrected activity of the pre-industrial wood sample: $i e$, the activity of a hypothetical wood sample grown in AD 1950, but otherwise identical with the pre-industrial wood sample. $\mathrm{A}^{*}{ }_{\text {wood }}$ is related to the oxalic acid standard by

$$
\mathrm{A}{ }^{*}{ }_{\text {wood }}=0.95 \mathrm{~A}{ }^{*}{ }_{\mathrm{OxT}}
$$

where $0.95 \mathrm{~A}_{\mathrm{OxT}}$ is the normalized oxalic acid activity $\left(\mathrm{A}_{\mathrm{ON}}\right)$. The value of $A_{O N}$ in the year $A D 1950$ is the absolute international standard activity $\left(\mathrm{A}_{\mathrm{abs}}\right)$ :

$$
\mathrm{A}_{\mathrm{abs}} \equiv \mathrm{A}^{*}{ }_{\mathrm{ON}} \equiv 0.95 \mathrm{~A}^{*}{ }_{\mathrm{OxT}} \equiv \mathrm{A}^{*}{ }_{\text {wood }}
$$

Using equations (3) and (4), equation (2) becomes

$$
\left.\mathrm{A}_{\mathrm{S}}\left\{\mathbf{R}_{\mathrm{ST}} / \mathbf{R}_{\mathrm{S}}\right\}^{\mathrm{b}}=\mathrm{A}_{\mathrm{atmT}}{ }^{(0)}\left\{\mathbf{R}_{\mathrm{ST}}{ }^{(0)} / \mathbf{R}_{\mathrm{atmT}}{ }^{(0)}\right\}^{\mathrm{b}} \exp \left(-\left(\mathbf{t}_{\mathrm{cal}}+\mathrm{y}-1950\right) / 8267\right)\right)
$$

To keep this derivation as general as possible we will not, at this stage, assume that the isotopic composition of the atmosphere has remained constant. Instead, we introduce the atmospheric anomaly parameter, $\beta$, defined by

$$
\beta=\frac{\mathrm{A}_{\mathrm{atm} \mathrm{T}^{(0)}}}{\mathrm{A}_{\mathrm{atm} \mathrm{T}^{\mathrm{pre}-\mathrm{ind}}}}\left\{\frac{\mathrm{R}_{\mathrm{atm}} \mathrm{T}^{\text {pre-ind }}}{\mathrm{R}_{\mathrm{atm} \mathrm{T}^{(0)}}}\right\}^{\mathrm{b}}
$$

$\beta$ would be unity if there were no significant local variations in the isotopic composition of the atmosphere and if both ${ }^{14} \mathrm{C}$ and ${ }^{13} \mathrm{C}$ levels of the atmosphere had remained constant. Using equations (6) and (7), equation (9) gives

$$
\mathrm{A}_{\mathrm{atmT}}{ }^{(0)}=\beta \mathrm{A}^{*}{ }_{\mathrm{ON}}\left\{\mathrm{R}_{\mathrm{atmT}^{(0)}} / 0.975 \mathrm{R}_{\mathrm{PDB}}\right\}^{\mathrm{b}}
$$

Substituting this into (8) gives

$$
\mathrm{A}_{\mathrm{S}}\left\{\mathrm{R}_{\mathrm{ST}} / \mathrm{R}_{\mathrm{S}}\right\}^{\mathrm{b}}=\beta \mathrm{A}^{*}{ }_{\text {oN }}\left\{\mathrm{R}_{\mathrm{ST}^{(}}{ }^{(0)} / 0.975 \mathrm{R}_{\mathrm{PDB}}\right\}^{\mathrm{b}} \exp \left(-\left(\mathrm{t}_{\mathrm{cal}}+\mathrm{y}-1950 / 8267\right)\right)
$$

The exponential term involving $(y-1950)$ is precisely the age correction between $\mathrm{A}^{*}{ }_{\mathrm{ON}}$ and $\mathrm{A}_{\mathrm{ON}}\left(\equiv 0.95 \mathrm{~A}_{\mathrm{OXT}}\right)$, so we have

$$
\mathrm{A}_{\mathrm{S}}\left\{\frac{0.975 \mathrm{R}_{\mathrm{PDB}}}{\mathrm{R}_{\mathrm{S}}}\right\}^{\mathrm{b}}=\beta \mathrm{A}_{\mathrm{ON}}\left\{\frac{\mathrm{R}_{\mathrm{ST}}{ }^{(0)}}{\mathrm{R}_{\mathrm{ST}}}\right\}^{\mathrm{b}} \quad \exp \left(-\mathrm{t}_{\mathrm{cal}} / 8267\right)
$$


The left-hand side of equation (12) defines the normalized sample activity, $\mathrm{A}_{\mathrm{SN}}$,

$$
\mathrm{A}_{\mathrm{SN}}=\mathrm{A}_{\mathrm{S}}\left\{\frac{0.975 \mathrm{R}_{\mathrm{PDB}}}{\mathrm{R}_{\mathrm{S}}}\right\}^{\mathrm{b}}
$$

which can be determined directly from the measured sample activity, $A_{S}$, and the corresponding ${ }^{13} \mathrm{C}$ ratio, $\mathrm{R}_{\mathrm{S}}$. Equation (12) becomes

$$
\mathrm{A}_{\mathrm{SN}}=\beta\left\{\frac{\mathrm{R}_{\mathrm{ST}}^{(0)}}{\mathrm{R}_{\mathrm{ST}}}\right\}^{\mathrm{b}} \quad \mathrm{A}_{\mathrm{ON}} \exp \left(-\mathrm{t}_{\mathrm{cal}} / 8267\right)
$$

This is a generalized dating equation which can easily be reduced to a more familiar form.

Since, in general, $\mathbf{R}_{\mathrm{ST}}$ is constant (ie, $\mathbf{R}_{\mathrm{ST}}=\mathbf{R}_{\mathrm{ST}}{ }^{\left({ }^{o}\right)}$ ) equation (14) can be simplified (except in the special cases discussed later) to

$$
\mathrm{A}_{\mathrm{SN}}=\beta \mathrm{A}_{\mathrm{ON}} \exp \left(-\mathrm{t}_{\mathrm{cal}} / 8267\right)
$$

Equation (15) is equivalent to the usual equation for age determination, but it differs in that the atmospheric anomaly parameter is retained (ie, no assumption is made regarding the constancy of the isotopic composition of atmospheric $\mathrm{CO}_{2}$ ) and the fractionation parameter is retained as an unspecified quantity ( $i e$, the assumption that $\mathrm{b}=2$ has not been made: although we have assumed that $b$ is the same for different kinds of fractionation, laboratory and natural). To apply equation (15), and to examine the effect of $b \neq 2$ on radiocarbon dating, it should be noted that equation (15), through $A_{O N}$, involves the true value of the oxalic standard rather than the measured value. The latter will, in general, incorporate the effect of laboratory fractionation during preparation (ie, conversion of oxalic acid to benzene or to a counting gas such as $\mathrm{CO}_{2}$ ); and this effect can be allowed for by using ${ }^{13} \mathrm{C}$ data and the relation

$$
\mathrm{A}_{\mathrm{OxT}} / \mathrm{A}_{\mathrm{Ox}}=\left\{\mathrm{R}_{\mathrm{OXT}} / \mathrm{R}_{\mathrm{Ox}}\right\}^{\mathrm{b}}
$$

Since by definition $\mathrm{R}_{\mathrm{OxT}}=0.981 \mathrm{R}_{\mathrm{PDB}}\left(i e, \delta^{13} \mathrm{C}_{\mathrm{OxT}}=-19 \%\right.$ PDB) this gives

$$
\mathrm{A}_{\mathrm{ON}}=0.95 \mathrm{~A}_{\mathrm{OxT}}=0.95 \mathrm{~A}_{\mathrm{Ox}}\left\{0.981 \mathrm{R}_{\mathrm{PDB}} / \mathrm{R}_{\mathrm{Ox}}\right\}^{\mathrm{b}}
$$

which allows $A_{O N}$ to be calculated from measured oxalic acid ${ }^{14} \mathrm{C}$ and ${ }^{13} \mathrm{C}$ data.

Slightly different forms of equation (15) are obtained if $\beta=1$. If $\beta=1$ then $t_{\text {cal }}$ must be replaced by the corrected radiocarbon age, $t^{(5730)}$, to give

$$
\mathrm{A}_{\mathrm{SN}}=\mathrm{A}_{\mathrm{ON}} \exp \left(-\mathrm{t}^{(5730)} / 8267\right)
$$

In terms of the conventional (5568-year half-life) radiocarbon age, $t$, the corresponding result is

$$
A_{S N}=A_{O N} \exp (-t / 8033)
$$

If $b=2$, then equations (17) and (18) reduce to the standard forms as given, for example, by Stuiver and Polach (1977). 
Note that $\beta$ is related to the difference between calendar age (= calibrated radiocarbon age) and corrected radiocarbon age: dividing (15) by (17) yields

$$
\mathrm{t}_{\mathrm{cal}}-\mathrm{t}^{(5730)}=8267 \ln \beta
$$

We will refer to this difference as the ${ }^{14} \mathrm{C}$ age anomaly.

A completely precise calculation of age requires $A_{O x}, R_{O x}, A_{S}$ and $R_{S}$ values (and a knowledge of $\beta$ ). In fact, published data generally give only the values of $t$, the conventional radiocarbon age, and $\mathbf{R}_{\mathrm{S}}$ (or its equivalent, $\delta^{13} \mathrm{C}_{\mathrm{S}}$ ) and it is not possible to regenerate the four original data values from only these two parameters. It is therefore not possible, in general, to correct published data for any deviation in $b$ from the assumed value of 2, although an approximate correction could be made. Nevertheless, it is a relatively simple matter to separately estimate the effect of $\mathrm{b} \neq 2$ on $\mathrm{A}_{\mathrm{ON}}$ and $\mathrm{A}_{\mathrm{SN}}$ determinations, and so estimate the effect on age determination for different values of $\mathbf{R}_{O_{\mathbf{x}}}$ and $\mathbf{R}_{\mathbf{S}}$. The results are presented in a later section.

\section{GROUNDWATER DATING AND THE RESERVOIR EFFECT}

It was noted earlier that additional complications arise in dating groundwaters or any material in which isotopic composition has been altered by processes other than radioactive decay. The simplest type of alteration occurs with post-depositional interaction (ie, mixing or isotopic exchange $^{3}$ ) with other ${ }^{14} \mathrm{C}$ reservoirs. This has been referred to as the reservoir effect. In the groundwater case, this situation is best illustrated by the input of (dead) carbon due to dissolution of carbonate minerals under closed (to $\mathrm{CO}_{2}$ ) system conditions, but other processes which are less easily identified as reservoir effects can have the same results. We will consider the groundwater case in detail in order to quantify these effects; the results, of course, have more general applicability, to items like shells, speleothems, etc.

In groundwater dating, following Wigley, Plummer, and Pearson (1978), age is determined by

$$
\mathrm{A}_{\mathrm{ST}}=\mathrm{A}_{\mathrm{ud}} \exp \left(\left(-\mathrm{t}_{\text {cal }}+\mathrm{y}-1950\right) / 8267\right)
$$

where $A_{\text {nd }}$ (which replaces $A_{S T}{ }^{(0)}$ in equation (2)) is the specific ${ }^{14} \mathrm{C}$ activity of the total dissolved carbon which would have occurred in the absence of radioactive decay. Equation (20) also applies to any material in which activity has been altered by a reservoir effect. It is convenient to introduce a factor, $\xi$, defined by

$$
\mathrm{A}_{\mathrm{nd}}=\xi \mathrm{A}_{\mathrm{ST}}{ }^{(0)}
$$

where $\xi$ accounts for all non-decay processes, either chemical or physical, which occur between isolation from the atmosphere (or soil atmosphere: or death, for the non-groundwater case) and sample collection. In ground-

\footnotetext{
3 "Exchange" is used here to mean both true exchange processes, which are uncommon, and chemical reactions which involve isotopic fractionation (eg, incongruent dissolution).
} 
water dating $\xi$ is called the adjustment factor. $\xi$ can be determined if one has sufficient knowledge of the past chemical and physical history of the sample. Methods for determining $\xi$ do not concern us here; they are discussed by Wigley, Plummer, and Pearson (1978). For groundwaters $\mathrm{A}_{\mathrm{ST}}{ }^{(0)}$ is the activity at the time of isolation from the atmospheric (or soil atmospheric) $\mathrm{CO}_{2}$ reservoir: $i e$, at the end of open (to $\left.\mathrm{CO}_{2}\right)$ system conditions during which changes in activity are determined solely by fractionation effects.

In deriving equation (15), we made the assumption that $R_{\mathrm{ST}}$ was a constant. When reservoir effects exist, this is no longer correct. A more general dating equation can be obtained directly from equation (14), noting that the adjustment factor, $\xi$, must be retained on the right-hand side because the conventional initial activity, $A_{\mathbf{S T}^{(0)}}{ }^{(0)}$, is replaced by $\xi \mathrm{A}_{\mathrm{ST}}{ }^{(0)}$ :

$$
\mathrm{A}_{\mathrm{SN}}=\xi \beta\left\{\frac{\mathrm{R}_{\mathrm{ST}^{(0)}}}{\mathrm{R}_{\mathrm{ST}}}\right\}^{\mathrm{b}} \quad \mathrm{A}_{\mathrm{ON}} \exp \left(-\mathrm{t}_{\mathrm{cal}} / 8267\right)
$$

This result differs from the earlier result, equation (15), in two ways: first, in the inclusion of a non-decay term $\xi$; and, second, in the term involving $\mathrm{R}_{\mathrm{ST}}{ }^{(0)} / \mathrm{R}_{\mathrm{ST}}$. The $\xi$ term accounts for changes in ${ }^{14} \mathrm{C}$ after death, or isolation from the atmosphere, due to non-decay processes. The $R_{S T}{ }^{(0)} /$ $\mathrm{R}_{\mathrm{ST}}$ term must be retained because such post-depositional non-decay processes will generally be accompanied by changes in sample ${ }^{13} \mathrm{C}$, and the assumption that $R_{S T}$ and $R_{S T}{ }^{(0)}$ are equal is no longer valid. Note that if $\beta$ is omitted from equation (22) then $t_{\text {cal }}$ must be replaced by $t^{(5730)}$, the corrected radiocarbon age.

In cases where there is a reservoir effect, if the conventional radiocarbon age is calculated using $A_{S N}$, and $A_{S N}$ is normalized using $R_{S}$, fractionation will not be correctly accounted for. The normalization procedure accounts for fractionation during sample formation (stable isotope change from $R_{\mathrm{atmT}}{ }^{(0)}$ to $\mathbf{R}_{\mathrm{ST}}{ }^{(0)}$ ), and during sample preparation ( $\mathbf{R}_{\mathrm{ST}}$ to $\mathbf{R}_{\mathrm{S}}$ ), and contains the implicit assumption that $\mathbf{R}_{\mathrm{ST}}{ }^{(0)}$ and $\mathbf{R}_{\mathrm{ST}}$ are equal. In reservoir effect situations and for groundwaters this is not correct, and equation (22) provides a more accurate basis for dating in these cases. Although the existence and importance of the non-decay term $\xi$ is wellknown, the term $\left\{\mathrm{R}_{\mathrm{ST}^{\mathrm{T}}}{ }^{(0)} / \mathrm{R}_{\mathrm{ST}}\right\}^{\mathrm{b}}$ seems to have been omitted in all previous discussions (including the literature on groundwater dating). Of course, $\mathrm{R}_{\mathrm{ST}}{ }^{(0)}$ can never be known precisely, but can only be estimated from a knowledge of the probable past history of a sample.

To determine the significance of the $\left\{\mathbf{R}_{\mathrm{ST}}{ }^{(0)} / \mathbf{R}_{\mathrm{ST}}\right\}^{\mathrm{b}}$ term, let us consider a simple groundwater example involving closed system congruent dissolution. We consider an example in which, for numerical simplicity, the dissolving mineral has $\delta^{13} \mathrm{C}=0 \%$. In this case $\xi$ is given by (eg, Ingerson and Pearson, 1964; Wigley, Plummer, and Pearson, 1978, p 1131)

$$
\xi=\frac{\delta^{13} \mathrm{C}_{\mathrm{ST}}}{\delta^{13} \mathrm{C}_{\mathrm{ST}}{ }^{(o)}}
$$


A typical situation might be one in which there was minimal isotopic evolution under open (to soil atmosphere $\mathrm{CO}_{2}$ ) system conditions, followed by closed system dissolution of calcite to near-saturation. In this case $\delta^{13} \mathrm{C}_{\mathrm{ST}}{ }^{(0)} \approx-22 \%$ and $\delta^{13} \mathrm{C}_{\mathrm{ST}} \approx-13 \%$ so that $\xi=0.5909$. For $\mathrm{b}=2$ the term $\left\{\mathrm{R}_{\mathrm{ST}}{ }^{(0)} / \mathrm{R}_{\mathrm{ST}}\right\}^{\mathrm{b}} \approx 0.9818$. The effect of $\xi$ in this case is considerable (more than 4300 years). The effect of $\left\{\mathbf{R}_{\mathbf{S T}}{ }^{(0)} / \mathbf{R}_{\mathrm{ST}}\right\}^{\mathrm{b}}$ is relatively small (ca 150 years), probably unimportant in most applications of groundwater dating, but more significant in other reservoir effect situations. Nevertheless, in a general theoretical development, one should be aware of the existence of even small terms.

To summarize, the usual dating procedure is to normalize the measured ${ }^{14} \mathrm{C}$ activity, $A_{\mathrm{S}}$, using the measured ${ }^{13} \mathrm{C}$ ratio, $\mathrm{R}_{\mathrm{s}}$. The corrected radiocarbon age can then be calculated using (equations (17) and (13))

$$
\mathrm{A}_{\mathrm{SN}}=\mathrm{A}_{\mathrm{S}}\left\{\frac{0.975 \mathrm{R}_{\mathrm{PDB}}}{\mathrm{R}_{\mathrm{S}}}\right\}^{\mathrm{b}}=\mathrm{A}_{\mathrm{ON}} \exp \left(-\mathrm{t}^{(5730)} / 8267\right)
$$

When reservoir effects occur equation (22) should be used. To compare it with equation (24), equation (22) can be written as

$$
\mathrm{A}_{\mathrm{S}}\left\{\frac{0.975 \mathrm{R}_{\mathrm{PDB}}}{\mathrm{R}_{\mathrm{ST}}{ }^{(0)}}\right\}^{\mathrm{b}}\left\{\frac{\mathrm{R}_{\mathrm{ST}}}{\mathrm{R}_{\mathrm{S}}}\right\}^{\mathrm{b}}=\xi \mathrm{A}_{\mathrm{ON}} \exp \left(-\mathrm{t}^{(5730)} / 8267\right)
$$

Written in this form it is apparent that, if there were no preparation fractionation (ie, $\mathbf{R}_{\mathrm{ST}}=\mathrm{R}_{\mathrm{S}}$ ), equation (22) or (25) amounts to normalizing $\mathrm{A}_{\mathrm{S}}$ using the initial ${ }^{13} \mathrm{C}$ ratio rather than the measured ${ }^{13} \mathrm{C}$ ratio, as in equation (24). Since $R_{S^{T}}{ }^{(0)}$ is frequently closer to $0.975 R_{\mathrm{PDB}}$ than it is to $\mathbf{R}_{\mathrm{S}}$, it is probably better to calculate dates without normalizing $\mathbf{A}_{\mathrm{S}}$ at all in reservoir or groundwater cases. This observation is made only as a point of interest, and is not a recommendation. The only completely acceptable procedure is to estimate $\xi$ and $R_{\mathrm{ST}}{ }^{(0)} / \mathbf{R}_{\mathrm{ST}}$ in each individual case, and use equation (22).

Note that, although the term $\left\{\mathbf{R}_{\mathrm{ST}}{ }^{(0)} / \mathbf{R}_{\mathrm{ST}}\right\}^{\mathrm{b}}$ has a relatively small effect, the adjustment due to its inclusion is of a similar magnitude to the adjustment arising from normalizing measured ${ }^{14} \mathrm{C}$ activities from $\mathrm{A}_{\mathrm{S}}$ to $\mathrm{A}_{\mathrm{SN}}$ using $\left\{\left(.975 \mathrm{R}_{\mathrm{PDB}}\right) / \mathbf{R}_{\mathrm{S}}\right\}^{\mathrm{b}}$. For consistency, if data are normalized in the usual way, then the term $\left\{\mathbf{R}_{\mathrm{ST}}{ }^{(0)} / \mathbf{R}_{\mathrm{ST}}\right\}^{\mathrm{b}}$ should also be considered.

$$
\text { EFFECTS OF } \mathrm{b} \neq 2
$$

The fractionation coefficient occurs in all terms in the dating equation introduced to account for fractionation effects. Such effects are accounted for in the normalization of the measured sample activity, in the normalization of the measured oxalic acid standard activity, in the postdepositional reservoir effect term involving $\mathrm{R}_{\mathrm{ST}}{ }^{(0)} / \mathrm{R}_{\mathrm{ST}}$, and in the atmospheric anomaly parameter.

The magnitude of the influence of possible variations in the fractionation coefficient, $\mathrm{b}$, can be calculated by examining various terms in 
the two dating equations derived above: viz that for routine samples (equation (15))

$$
\mathrm{A}_{\mathrm{SN}}=\beta \mathrm{A}_{\mathrm{ON}} \exp \left(-\mathrm{t}_{\mathrm{cal}} / 8267\right)
$$

and that for groundwaters or samples affected by post-depositional nondecay processes (equation (22))

$$
\mathrm{A}_{\mathrm{SN}}=\xi \beta\left\{\frac{\mathrm{R}_{\mathrm{ST}}{ }^{(0)}}{\mathrm{R}_{\mathrm{ST}}}\right\}^{\mathrm{b}} \quad \mathrm{A}_{\mathrm{ON}} \exp \left(-\mathrm{t}_{\text {cal }} / 8267\right)
$$

The coefficient $b$ appears in $A_{\mathrm{SN}}, A_{\mathrm{ON}}, \beta$ and $\left\{\mathrm{R}_{\mathrm{ST}}{ }^{(0)} / \mathrm{R}_{\mathrm{ST}}\right\}^{\mathrm{b}}$.

To evaluate the effect of $b \neq 2$ we first take the natural logarithm of equation (22) and then differentiate with respect to $b$. The incremental change in $t_{\text {cal }}$ due to a change in $b$ is given by

$$
\Delta \mathrm{t}_{\mathrm{eal}}=8267 \Delta \mathrm{b}\left[-\frac{\partial}{\partial \mathrm{b}}\left(\ln \mathrm{A}_{\mathrm{SN}}\right)+\frac{\partial}{\partial \mathrm{b}}\left(\ln \mathrm{A}_{\mathrm{ON}}\right)+\frac{\partial}{\partial \mathrm{b}}(\ln \beta)+\ln \frac{\mathrm{R}_{\mathrm{ST}}^{(0)}}{\mathrm{R}_{\mathrm{ST}}}\right]
$$

The effect of $b \neq 2$ may be described in terms of the associated age "error", E, defined as

$$
\mathrm{E}=\mathrm{t}_{\mathrm{cal}}-\mathrm{t}_{\mathrm{cal}(\mathrm{b}=2)}
$$

where $t_{\mathrm{cal}(\mathrm{b}=2)}$ is the estimated calendar age using $b=2$. From equation (26) it can be seen that $\mathrm{E}$ can be split up into errors arising individually from $A_{\mathrm{SN}}, A_{O N}, \beta$ and $\left\{R_{\mathrm{ST}}{ }^{(0)} / \mathrm{R}_{\mathrm{ST}}\right\}^{\mathrm{b}}$; namely $\mathrm{E}_{1}, \mathrm{E}_{2}, \mathrm{E}_{3}$, and $\mathrm{E}_{4}$ in the following equations which have been derived from (26) using (13), (16) and (9).

where ${ }^{4}$

$$
\mathrm{E}=\mathrm{E}_{1}+\mathrm{E}_{2}+\mathrm{E}_{3}+\mathrm{E}_{4}
$$

$$
\begin{gathered}
\mathrm{E}_{1}=-8267(\mathrm{~b}-2) \ln \left(0.975 \mathrm{R}_{\mathrm{PDB}} / \mathrm{R}_{\mathrm{S}}\right) \approx 8.267(\mathrm{~b}-2)\left(\delta^{13} \mathrm{C}_{\mathrm{S}}+25\right) \\
\mathrm{E}_{2}=8267(\mathrm{~b}-2) \ln \left(0.981 \mathrm{R}_{\mathrm{P} \cdot \mathrm{DB}} / \mathrm{R}_{\mathrm{Ox}}\right) \approx-8.267(\mathrm{~b}-2)\left(\delta^{13} \mathrm{C}_{\mathrm{Ox}}+19\right) \\
\mathrm{E}_{3}=8267(\mathrm{~b}-2) \ln \left(\mathrm{R}_{\mathrm{atmT}}{ }^{\mathrm{pre}-\mathrm{ind}} / \mathrm{R}_{\mathrm{atmT}}{ }^{(0)}\right) \approx \\
-8.267(\mathrm{~b}-2)\left({ }^{13} \mathrm{C}_{\mathrm{atmT}}{ }^{(0)}-\delta^{13} \mathrm{C}_{\mathrm{atmT}}{ }^{\text {pre-ind }}\right) \\
\mathrm{E}_{4}=8267(\mathrm{~b}-2) \ln \left(\mathrm{R}_{\mathrm{ST}}{ }^{(0)} / \mathrm{R}_{\mathrm{ST}}\right) \approx-8.267(\mathrm{~b}-2)\left(\delta^{13} \mathrm{C}_{\mathrm{ST}_{\mathrm{T}}}-\delta^{13} \mathrm{C}_{\mathrm{ST}}{ }^{(0)}\right)
\end{gathered}
$$

We will consider $\mathrm{E}_{1}, \mathrm{E}_{2}, \mathrm{E}_{3}$, and $\mathrm{E}_{4}$ separately.

\section{Influence through $A_{\mathrm{SN}}$}

The normalized sample activity accounts for natural fractionation in the sample during its formation and laboratory fractionation during sample preparation. The age error arising from this term when $\mathrm{b} \neq 2, \mathrm{E}_{1}$, is given by equation (28). $\mathrm{E}_{1}$ is shown as a function of measured sample ${ }^{13} \mathrm{C}$ ratio, $\delta^{13} \mathrm{C}_{\mathrm{S}}$, for various values of $\mathrm{b}$ in figure 1 .

1 The approximations in terms of $\delta^{13} \mathrm{C}$ values result from application of the approximations $(1+\mathrm{x})^{-1} \approx 1-\mathrm{x}$ and $\ln (1+\mathrm{x}) \approx \mathrm{x}$, valid for small $\mathrm{x}$. 
Saliège (Saliège and Fontes, ms in preparation) has obtained values of $b \approx 2.6 \pm 0.2$ for $C 3$ plants (beans) and $2.3 \pm 0.2$ for C4 plants (corn). Radnell (1980) has found a range of values of $b$ for different stages of the preparation of benzene from oxalic acid for routine ${ }^{14} \mathrm{C}$ dating. For benzene distillation from the trimerization catalyst, even after discarding one anomalously high value, his $b$ value is $2.43 \pm 0.15$. For these values of b the dating error may be as high as 100 years for samples rich in ${ }^{13} \mathrm{C}$ relative to wood ( $c f$ figure 1).

\section{Influence through $A_{\mathrm{ON}}$}

The normalized oxalic acid activity is necessary to account for frac. tionation during preparation of this standard. The age error arising from this term when $b \neq 2, E_{2}$, is given by equation (29). Figure 2 shows $E_{2}$ as a function of measured oxalic acid ${ }^{13} \mathrm{C}$ ratio, for $\delta^{13} \mathrm{C}_{\mathrm{Ox}}$ ranging from $-12 \%$ to $-26 \%$. Proper preparation techniques rarely give fractionations over $1 \%$, and even with $b=2.6$, the associated error of ca 5 years is insignificant ( $c f$ figure 2).

\section{Influence through $\beta$}

Here the influence is not on the ${ }^{14} \mathrm{C}$ date, since dates are generally given based on the assumption of constant atmospheric isotopic composition. The effect of $b \neq 2$ enters in the interpretation of the ${ }^{14} \mathrm{C}$ anomaly (calendar age minus corrected radiocarbon age) in terms of changes in atmospheric ${ }^{14} \mathrm{C}$ activity. From equation (30), a $1 \%$ change in atmospheric ${ }^{13} \mathrm{C}$ level would correspond to an error in the age anomaly of only 3.3 years if $\mathrm{b}$ were 2.4 . This is equivalent to an atmospheric ${ }^{14} \mathrm{C}$ change of $0.4 \%$, much less than the values inferred from tree-ring dating, and well beyond the limits of current ${ }^{14} \mathrm{C}$ dating accuracy.

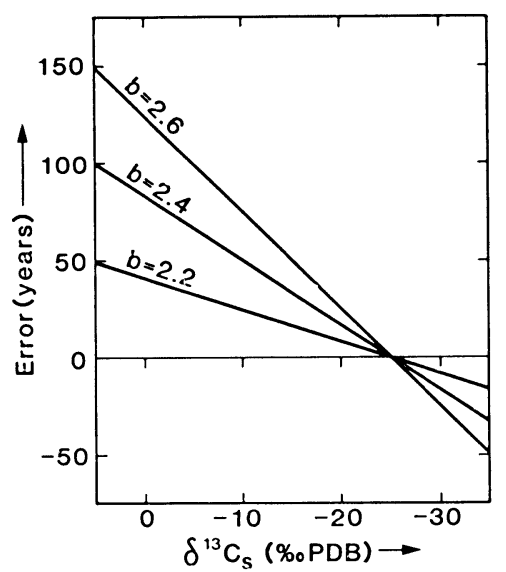

Fig 1. Age error resulting from the assumption that $b=2$ for different hypothetical b values: term arising from laboratory and natural fractionation of the sample (eq (28)). 
Influence through $\left\{\mathbf{R}_{\mathrm{ST}}{ }^{(0)} / \mathbf{R}_{\mathrm{ST}}\right\}^{\mathrm{b}}$

This term accounts for post-depositional stable isotope changes which can occur in reservoir effect situations or in groundwaters. It arises because the effects of fractionation during formation of the sample are accounted for using $\mathrm{R}_{\mathrm{ST}}$ instead of $\mathrm{R}_{\mathrm{ST}}{ }^{(\mathrm{o})}$. It corrects for any process which might alter the stable isotope ratio after formation, mixing with another carbon reservoir or isotopic exchange processes being the most common. We have already shown that, with $b=2$, neglect of this term can lead to errors of up to 150 years. If $\mathrm{b} \neq 2$, further (but relatively smaller) errors may arise, determined by equation (31). Values of $\mathbf{E}_{4}$ for various $b$ and $\left(\delta^{13} \mathrm{C}_{\mathrm{ST}}-\delta^{13} \mathrm{C}_{\mathrm{ST}}{ }^{(0)}\right)$ values are shown in figure 3 , and may range up to 50 years or more.

\section{THE ATMOSPHERIC ANOMALY PARAMETER}

One of the assumptions of conventional radiocarbon dating is that the atmospheric ${ }^{14} \mathrm{C}$ level has remained constant in the past. There is

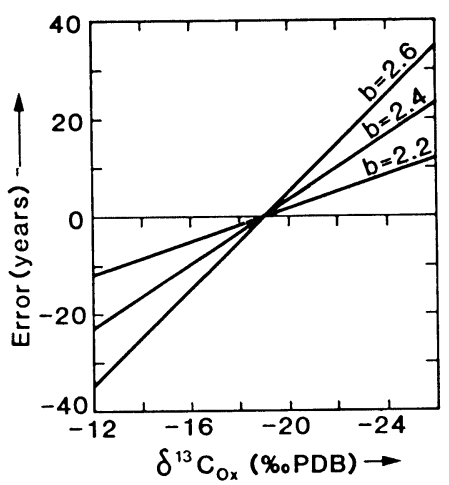

Fig 2 Age error resulting from the assumption that $b=2$ for different hypothetical b values: term arising from laboratory fractionation of the oxalic acid standard (eq (29)).

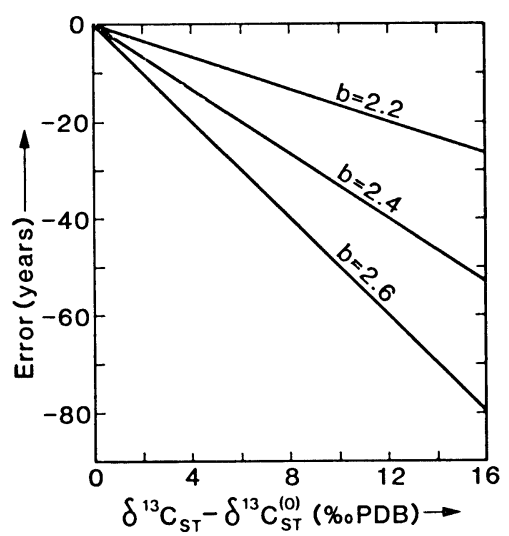

Fig 3. Age error resulting from the assumption that $b=2$ for different hypothetical b values: term arising from post-depositional stable isotope changes (eq (31)). 
strong evidence that this is not correct (eg, Stuiver and Quay, 1980; Suess, 1980; de Jong and Mook, 1980; Bruns, Münnich, and Becker, 1980). Although rarely stated explicitly, the assumption of constant ${ }^{13} \mathrm{C}$ level is also inherent in the method. If one allows the isotopic composition (ie, ${ }^{13} \mathrm{C}$ and ${ }^{14} \mathrm{C}$ ) of atmospheric $\mathrm{CO}_{2}$ to vary, then the term (equation $(9)$ )

$$
\beta=\frac{\mathrm{A}_{\mathrm{atmT}}{ }^{(0)}}{\mathrm{A}_{\mathrm{atm}_{\mathrm{T}} \mathrm{T}^{\text {pre-ind }}}}\left\{\frac{\mathrm{R}_{\mathrm{atm} \mathrm{T}^{\text {pre-ind }}}}{\mathrm{R}_{\mathrm{atm} \mathrm{T}^{(0)}}}\right\}^{\mathrm{b}}
$$

appears in the conventional dating formula (see equation (15)). The value of $\beta$ (the atmospheric anomaly parameter) can be determined experimentally by dating material of known calendar age (such as tree rings). If $t_{c a l}$ is the calendar age and $t^{(5730)}$ is the corrected radiocarbon age then (equation (19))

$$
\triangle \mathrm{t}=\mathrm{t}_{\mathrm{cal}}-\mathrm{t}^{(5730)}=8267 \ln \beta
$$

defines the age anomaly, $\Delta \mathrm{t}$.

When $\Delta_{t}$ is positive the immediate implication is that $A_{a t m T}{ }^{(0)}$, the atmospheric ${ }^{14} \mathrm{C}$ activity $\mathrm{t}_{\mathrm{cal}}$ years prior to 1950 , was greater than $A_{a t m T^{p r e-i n d}}$, the pre-industrial value. But equation (9) shows that part of $\Delta t$ may be explained by variations in $R_{a t m T}$. To explain an anomaly of 100 years in terms of ${ }^{14} \mathrm{C}$ changes alone would require $\mathrm{A}_{\mathrm{atmT}}{ }^{(0)}=0.988$

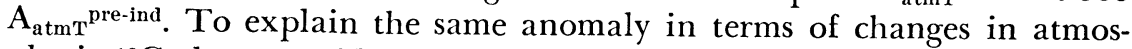
pheric ${ }^{13} \mathrm{C}$ alone would require $\delta^{13} \mathrm{C}_{\mathrm{atmT}}{ }^{(0)}=13 \%$ (assuming $\delta^{13} \mathrm{C}_{\mathrm{atTm}}$ preind $=-7 \%$, and using $\mathrm{b}=2$ ). Such a change in atmospheric ${ }^{13} \mathrm{C}$ is an order of magnitude greater than any changes which might have occurred in the past 10,000 years.

Various estimates have been made (using tree-ring data) of variations in atmospheric ${ }^{13} \mathrm{C}$ over the past 100 years or so, attributed to fossil fuel burning and/or biospheric changes (see, eg, Stuiver, 1978). Direct atmospheric measurements (Keeling, Mook, and Tans, 1979) show a decrease of ca $0.6 \%$ over the period 1956 to 1978 . Such a change would result in an age anomaly of only 10 years, so it is apparent that changes in atmospheric ${ }^{14} \mathrm{C}$ dominate in determining the age anomaly.

The age anomaly is of considerable importance since it may be a proxy indicator of past variations in solar activity, and, possibly, of terrestrial climate (see, eg, Eddy, 1977: although more recent work by Stuiver, 1980, and by Williams, Wigley, and Kelly, 1980, has failed to confirm a simple age anomaly-climate link). An examination of changes in the age anomaly over the past 8000 years (the age of the oldest accurately dated tree-ring samples) shows two distinct types of variation: long-term changes on a time scale of millennia attributed to changes in the earth's magnetic field (Barbetti, 1980), and superimposed short-term fluctuations attributed to changes in solar activity (Stuiver and Quay, 1980). It is possible that part of these short-term fluctuations has arisen from systematic dating errors resulting from the assumption that $b=2$ and fluctuations in $\delta^{13} \mathrm{C}_{\mathrm{S}}$ values of dated tree-ring samples. 
To show this, we need to derive an expression for the measured age anomaly; $i e$, the difference between $\mathrm{t}_{\mathrm{cal}}$ and $\mathrm{t}_{\mathrm{b}=2}{ }^{(5730)}$, rather than $\Delta \mathrm{t}$. From equation (15), using (13) and (16), we have

$$
\mathrm{A}_{\mathrm{S}}\left\{\frac{0.975 \mathrm{R}_{\mathrm{PDB}}}{\mathrm{R}_{\mathrm{S}}}\right\}^{\mathrm{b}}=\beta 0.95 \mathrm{~A}_{\mathrm{Ox}}\left\{\frac{0.981 \mathrm{R}_{\mathrm{PDB}}}{\mathrm{R}_{\text {Ox }}}\right\}^{\mathrm{b}} \exp \left(-\mathrm{t}_{\mathrm{cal}} / 8267\right)
$$

If $\beta$ is omitted, then $t_{\text {cal }}$ must be replaced by $t^{(5730)}$. Further, if $b$ is assumed equal to 2 , then $t_{b=2}{ }^{(5730)}$ should be used. Hence, we have

$$
\mathrm{A}_{\mathrm{S}}\left\{\frac{0.975 \mathrm{R}_{\mathrm{PDB}}}{\mathrm{R}_{\mathrm{S}}}\right\}^{2}=0.95 \mathrm{~A}_{\mathrm{Ox}}\left\{\frac{0.981 \mathrm{R}_{\mathrm{PDB}}}{\mathrm{R}_{\mathrm{Ox}}}\right\}^{2} \exp \left(-\mathrm{t}_{\mathrm{b}=2}{ }^{(5730)} / 8267\right)
$$

Dividing (33) and (34) and taking natural logarithms gives

$$
\mathrm{t}_{\mathrm{cal}}-\mathrm{t}_{\mathrm{b}=2}{ }^{(5730)} \equiv \Delta \mathrm{t}_{\mathrm{b}=2}=8267(\mathrm{~b}-2) \ln \left(\frac{0.981 \mathrm{R}_{\mathrm{S}}}{0.975 \mathrm{R}_{\mathrm{Ox}}}\right)+8267 \ln \beta \text {. }
$$

$\Delta t_{b=2}$ differs from $\Delta_{t}(\equiv 8267 \ln \beta$; equation (32)) because radiocarbon ages are calculated using $\mathrm{b}=2$. This difference is manifest in the first term on the right-hand side of equation (35) the value of which may be up to 20 years for representative values of $R_{S}$ and $R_{0 x}$ if $b$ were as large as 2.4. It is possible, therefore, that deviations from $b=2$ might be noticeable in an analysis of $\Delta_{\mathrm{t}}$ data.

To examine this possibility further, we need to distinguish the two distinct parts of the age anomaly, the long-term trend and the short-term fluctuations, denoted below by $\Delta t_{\mathrm{LT}}$ and $\Delta \mathrm{t}_{\mathrm{ST}}$, respectively. If we assume that differences between $R_{O x}$ and $R_{O x T}$ are small compared with differences between $R_{S}$ and the standard, $0.975 R_{\mathrm{PDB}}$, then equation (35) can be written as

$$
\mathrm{Y}={ }_{\triangleleft} \Delta \mathrm{t}_{\mathrm{b}=2}-\Delta \mathrm{t}_{\mathrm{LT}} \approx 8.267(\mathrm{~b}-2)\left(\delta^{13} \mathrm{C}_{\mathrm{s}}+25\right)+\Delta \mathrm{t}_{\mathrm{ST}}
$$

$\mathrm{Y}$ and $\delta^{13} \mathrm{C}_{\mathrm{S}}$ can be obtained from tree-ring-based age anomaly data given in the tables of, eg, Michael and Ralph (1974) and Suess (1978). If $\Delta \mathrm{t}_{\mathrm{ST}}$ does not vary systematically with $\delta^{13} \mathrm{C}_{\mathrm{S}}$, then, if $\mathrm{b}$ is significantly greater than 2, repression of $\mathrm{Y}$ against $\left(\delta^{13} \mathrm{C}_{\mathrm{S}}+25\right)$ should produce a line with slope $8.267(\mathrm{~b}-2)$ and a significant positive correlation coefficient, provided that the sample size is large enough. (A significant correlation would not, however, offer conclusive proof of $b \neq 2$, since such a correlation might arise if parallel fluctuations in tree-ring ${ }^{14} \mathrm{C}$ and ${ }^{13} \mathrm{C}$ were caused by some common external geochemical or geophysical factor.)

For any statistically significant regression slope to be identified with (b-2), its value would have to be of order 1 to $5\left(\mathrm{yr}(\% \circ)^{-1}\right)$ : $\mathrm{b}=2.1$ would give a slope of ca 0.8 and $b=2.6$ a slope of ca 5.0. These values place a constraint on the correlation coefficient, $r$, since

$$
\mathrm{r}=\mathrm{a} \sigma_{\mathrm{X}} / \sigma_{\mathrm{Y}}
$$

where a is the slope of the regression line and $\sigma_{\mathrm{X}}$ and $\sigma_{\mathrm{Y}}$ are the standard deviations of $\mathrm{X}\left(i e, \delta^{13} \mathrm{C}_{\mathrm{S}}\right)$ and $\mathrm{Y}$. An examination of data given by 
Michael and Ralph (1974) and Suess (1978) shows that $\sigma_{X} \sim 2 \%$ and $\sigma_{\mathrm{Y}} \sim 100 \mathrm{yr}$. Thus, for the slope to lie between 1 and $5, \mathrm{r}$ must be between 0.02 and 0.10 . In other words, any correlation coefficient which can be identified with $a b \neq 2$ effect must not only be statistically significant, but cannot exceed 0.1 . For such a low correlation coefficient to be statistically significant at, say, the $5 \%$ level, the sample size would have to be very large, at least 200, and considerably larger if b were closer to 2 than 2.6.

In spite of the fact that there are insufficient data available to test the hypothesis that $b \neq 2$ using age anomaly data, we have examined the relationship between $\mathrm{Y}$ and $\delta^{13} \mathrm{C}_{\mathrm{S}}$ using the data given by Michael and Ralph (1974) and by Suess (1980). We considered only the bristlecone pine data given by these authors (to eliminate any possible speciesdependent effects) and eliminated a small number of possibly suspect data points (low yield cases in the Michael and Ralph data, and cases with large differences between the two counters used by Suess). For the Suess data we found no significant correlation $(r=-0.04$ for $n=181$ ) even when the data were stratified according to count-rate standard deviation. For the Michael and Ralph data the correlation coefficient was -0.22 $(n=113$; regression slope, -10.8$)$ which is significant at the $5 \%$ level. This value is too large to be attributed to $a b \neq 2$ effect, and would, in any case, indicate that $b$ was less than 2 .

Although these results do not prove that $b \neq 2$ is incorrect, they do show that, even in this high precision application of radiocarbon dating, the effect of any deviation of $b$ from the generally assumed value of 2 is beyond detection using currently available data.

\section{CONCLUSION}

The aim of this paper was to explore the implications of a difference in the ${ }^{14} \mathrm{C} /{ }^{13} \mathrm{C}$ fractionation coefficient, $\mathrm{b}$, from the accepted value of 2 . Although theoretical grounds for expecting $b$ to differ significantly from 2 are meager recent experimental work by Radnell (1980) and by Saliège (Saliège and Fontes, $\mathrm{ms}$ in preparation) has suggested the possibility of $b \neq 2$.

In order to examine the effects of $b \neq 2$, we have rederived all of the usual expressions used in ${ }^{14} \mathrm{C}$ dating, retaining $\mathrm{b}$ as an unspecified parameter. Variations in $b$ have been shown to affect the radiocarbon age in three ways: through differences in the measured sample ${ }^{13} \mathrm{C}$ ratio (ie, $\delta^{13} \mathrm{C}_{\mathrm{S}}$ ) from the standard 25\%; through fractionation of the oxalic acid standard; or through non-decay changes in the true sample isotopic composition between initial isolation from the atmosphere and measurement (reflected in the ${ }^{13} \mathrm{C}$ ratio change $\left(\delta^{13} \mathrm{C}_{\mathrm{ST}}-\delta^{13} \mathrm{C}_{\mathrm{ST}}{ }^{(0)}\right)$ ).

The first of these factors is shown in figure 1 . Even if $b$ were as large as 2.4 , the maximum age error resulting from the assumption that $b=2$ would be less than 50 years. For most applications, this is unimportant. For tree-ring samples, in which precise dating may be necessary in calibrating the radiocarbon time-scale, $\delta^{13} \mathrm{C}_{\mathrm{S}}$ is rarely outside the range 
$-20 \%$ to $-30 \%$ and the error would, therefore, rarely exceed 20 years (for $b=2.4$ ).

The $b \neq 2$ influence through oxalic acid fractionation is shown in figure 2. Since this fractionation rarely exceeds $1 \%$, the maximum error is \pm 3 years (for $b=2.4$ ), entirely negligible.

The influence arising from non-decay processes is only likely to be important in groundwaters and other reservoir effect cases, where postisolation processes, other than radioactive decay, have caused a significant change in isotopic composition. Figure 3 shows that the age error, even in extreme cases, is unlikely to exceed 50 years. Once again, for such cases, where many other dating uncertainties generally exist, this is relatively insignificant.

Although we feel that it is important to have a completely general theory for the correction of fractionation effects in radiocarbon dating, it is apparent from these results that, given the other uncertainties in dating, the possible effect of $b \neq 2$ is almost always insignificant. The only exception to this rule may arise in tree-ring dating for calibration of the radiocarbon time-scale or for determining the past history of atmospheric ${ }^{14} \mathrm{C}$ fluctuations. Here, errors of up to 20 years may occur if b is significantly greater than 2. However, a statistical analysis of published treering dates has revealed no systematic relationship with $\delta^{13} \mathrm{C}_{\mathrm{S}}$ as might be expected if $b \neq 2$. We conclude, therefore, that the effect of $b \neq 2$, if it exists, is unimportant even in this application.

\section{REFERENCES}

Barbetti, Mike, 1980, Geomagnetic strength over the last 50,000 years and changes in atmospheric ${ }^{14} \mathrm{C}$ concentration: Emerging trends, in Stuiver, Minze and Kra, Renee, athos. Proc: Radiocarbon, v 22, no. 2, p 192-199.

Bigeleisen, J and Mayer, M G, 1947, Calculation of equilibrium constants for isotopic exchange reactions: Jour Chem Physics, v 15, p $261-267$.

Bruns, Michael, Mïnnich, K O, and Becker, Bernd, 1980, Natural radiocarbon variations from AD 200 to 800 , in Stuiver, Minze and Kra, Renee, eds, Internatl radiocarbon conf, 10th, Proc: Radiocarbon, v 22, no. 2, p 273-277.

Craig, Harmon, 1954, Carbon-13 in plants and the relationships between carbon-13 and carbon-14 in nature: Jour Geol, v 62, p 115-149.

Eddy, J A, 1977, Climate and the changing sun: Climatic Change, v 1, p 173-190.

Galimov, E M, 1978, Paper, Internatl geol, cosmochronol, and isotope geol conf, 4th: Snowmass, Colorado.

Ingerson, F and Pearson, F J, Jr, 1964, Estimation of age and rate of motion of ground water by the ${ }^{14} \mathrm{C}$ method, in Recent researches in the fields of hydrosphere, atmosphere and nuclear chemistry: Maruzen, Japan, p 263-283.

e Stuiver, Minze and Kra, Renee, eds, Internatl radiocarbon conf, 10th, Proc: Radiocarbon, v 22, no. 2, p 267-272.

keeling C D, Mook, W $G$, and Tans, P P, 1979, Recent trends in the ${ }^{13} \mathrm{C} /{ }^{12} \mathrm{C}$ ratio of atmospheric carbon dioxide: Nature, v 277, p 121-123.

Michael, H N and Ralph, E K, 1974, University of Pennsylvania radiocarbon dates XVI: Radiocarbon, v 16, p. 198-218.

Radnell, C J, 1980, The isotopic fractionation of ${ }^{14} \mathrm{C}$ and ${ }^{13} \mathrm{C}$ relative to ${ }^{12} \mathrm{C}$, in Slater, E A and Tate, J O, eds, Internatl, symposium on Archaeometry and Archaeol, Prospection, 16:h, Proc, p 360-392.

Richet, P, Bottinga, Y, and Javoy, M, 1977, A review of hydrogen, carbon, nitrogen, oxygen, sulphur and chlorine stable isotope fractionation among gaseous molecules: Ann Rev Earth Planetary Sci, v 5, p 65-110.

Stuiver, Minze, 1978, Atmospheric carbon dioxide and carbon reservoir changes: Science, v 199, p 253-258. 
Stuiver, Minze, 1980, Solar variability and climatic change during the current millennium: Nature, v 286, p 868-871.

Stuiver, Minze and Polach, H A, 1977, Reporting of ${ }^{14} \mathrm{C}$ data: Radiocarbon, v 19, p 355-363.

Stuiver, Minze and Quay, P D, 1980, Changes in atmospheric carbon-14 attributed to a variable sun: Science, v 207, p 11-19.

Stuiver, Minze and Robinson, S W, 1974, University of Washington GEOSECS North Atlantic carbon-14 results: Earth Planetary Sci Letters, v 23, p 87-90.

Suess, H E, 1978, La Jolla measurements of radiocarbon in tree-ring dated wood: Radiocarbon, v 20, p 1-18.

1980, The radiocarbon record in tree rings of the last 8000 years, in Stuiver, Minze and Kra, Renee, eds, Internatl radiocarbon conf, 10th, Proc: Radiocarbon, v 22, no. 2, p 200-209.

Thiemens, M H and Clayton, R N, 1979, A search for isotopic nuclear spin effects (abs): Meteoritics, v 14, p 545-547.

Turro, N J and Traeutler, B, 1978, Magnetic isotope and magnetic field effects on chemical reactions. Sunlight and soap for the efficient separation of ${ }^{13} \mathrm{C}$ and ${ }^{12} \mathrm{C}$ isotopes: Jour Am Chem Soc, v 100, p 7432-7434.

Urey, H C, 1947, The thermodynamic properties of isotopic substances: Jour Chem Soc, p 562-581.

Wigley, T M L, Plummer, L N, and Pearson, F J, 1978, Mass transfer and carbon isotope evolution in natural water systems: Geochim et Cosmochim Acta, v 42, p
$1117-1139$.

Williams, L D, Wigley, T M L, and Kelly, P M, 1980, Climatic trends at high northern latitudes during the last 4000 years compared with ${ }^{14} \mathrm{C}$ fluctuations, in Sun and climate: Toulouse, France, C N E S, p 11-20. 